McMillan for his co-operation, and help in planning the study, and, together with Dr. Alan Johnson and Dr. Neville Conway, for permission to study patients under their care at the Southampton Chest Hospital Wessex Regional and Thoracic Centre; our thanks are also due to the staff of the theatre for their assistance and to Mr. Brian Augier for statistical advice.

This work was supported by a grant from the British Heart Foundation to one of us (P.T.)

\section{References}

Bettinger, J. C., Surawicz, B., Brylogle, S. W., Anderson, N., jun., and Bellet, S. (1956). American fournal of Medicine, 21, 521.

Ceremuzynski, L Staszewska-Barczac, J., and Herbaczynska-Cedro, $\mathrm{K}$ (1969). Cardiovacsular Research, 3, 190

Cotlove, E., Trantham, H. V., and Bowman, R. L. (1958). Fournal of Laboratory and Clinical Medicine, 51, 461.

Cox, W. V., and Robertson, H. F. (1936). American Heart fournal, 12, 285 Dennis, J., and Moore, R. M. (1938). American fournal of Physiology, $125,443$.

Ebert, P. A., Vanderbeek, R. B., Allgood, R. J., and Sabiston, D. C., jun (1970). Cardiovascular Research, 4, 141

Flear, C. T. G., and Florence, I. (1961). Clinica Chimica Acta, 6, 129.

Harris, A. S. (1966). American Heart fournal, 71, 797.

Harris, A. S., Bisteni, A., Russell, R. A., Brigham, J. C., and Firestone, J. E. (1954). Science, 119, 200.

Hoffman, B. F., and Cranefield, P. F. (1960). Electrophysiology of the Heart. New York, McGraw-Hill.
Iseri, L. T., Alexander, L. C., McCaughley, R. S., Boyle, A. J., and Myers, G. B. (1952). American Heart fournal, 43, 215.

Jennings, R. B., Sommers, H. M., Kaltenbach, J. P., and West, J. J. (1964). Circulation Research, 14, 260.

Klein, R., Haddown, J. E., Kind, C., and Cockburn, F. (1968). Metabolism, $17,1094$.

Langer, G. A. (1968). Physiology Review, 48, 708.

Levine, H. D., Merril, J. P., and Somerville, W. (1951). Circulation, 3, 889

McVie, J. G. (1970). fournal of Clinical Pathology, 23, 203.

Mandal, A. K., Callaghan, J. C., Dolan, A. M., and Sterns, L. P. (1969). Annals of Thoracic Surgery, 7, 428.

Paradise, R. R. (1963). Nature, 198, 112.

Prasad, K., and Callaghan, J. C. (1969). Annals of Thoracic Surgery, 7, 571. Raab, W. (1969). Annals of the New York Academy of Science, 147, 672.

Regan, T. J., Harman, M. A., Lehen, P. H., Burke, W. M., and Olderwortel, H. A. (1967). Fournal of Clinical Investigation, 46, 1957.

Schaal, S. F., Wallace, A. G., and Sealy, W. C. (1969). Cardiovascular Research, 3, 241

Shanks, R. G., and Dunlop, D. (1967). Cardiovascular Research, 1, 34.

Singh, C. M., Flear, C. T. G., and Ross, D. (1969). Second Annual Meeting of the International Study Group for Research in Cardiac Metabolism, p. 31. Pavia, Succ. Fusi.

Surawicz, B. (1966). Progress in Cardiovascular Diseases, 8, 364.

Taggart, P., and Slater, J. D. H. (1970). Clinical Science, 38, $26 \mathrm{P}$

Taggart, P., and Slater, J. D. H. (1971). In preparation.

Thomas, M., Shulman, G., and Opie, L. (1970). Cardiovascular Research, 4, 327 .

Vanderbeek, R. B., and Ebert, P. A. (1970). American fournal of Physiology,

Vick, R. L., Hazlewood, C. F., and Nichols, B. L. (1970). Circulation Research, 27, 159

Zugibe, F. T., Bell, P., jun., Conley, T., and Standish, M. L. (1966). Archives of Pathology, 81, 409.

\title{
Smoking Risks of Different Tobaccos
}

\section{R. D. PASSEY, MICHAEL BLACKMORE, DAVID WARBRICK-SMITH, RAYMOND JONES}

British Medical fournal, 1971, 4, 198-201

\section{Summary}

The smoke of English cigarettes (flue-cured tobacco) greatly shortens the life of rats and damages the respiratory system, whereas that of the cigar (air-cured tobacco) is relatively harmless. This bears out two of the principal features in the 1971 Report of the Royal College of Physicians, which draws attention to the large number of premature deaths in cigarette smokers and the comparative safety of smoking cigars.

\section{Introduction}

Before the present century lung cancer did not excite undue interest and presumably was reasonably constant in its incidence and mortality rate. This is no longer so. At the beginning of this century cancer of the lung was regarded as a rare disease. Now, in many countries, it is common, and in Britain it is the commonest recorded form of cancer in males. It is generally accepted that the increase is the result of the world-wide increase in the smoking of cigarettes. Yet cigarettes were being commonly smoked in the early years of the century.

Why is the ordinary cigarette itself so dangerous? In the Report of the Advisory Committee to the Surgeon-General on

Chester Beatty Research Institute, London S.W.3

R. D. PASSEY, M.D., D.P.H., Emeritus Professor of Experimental Pathology (Professor Passey died on 1 September 1971)

MICHAEL BLACKMORE, M.B., B.S., Research Assistant

DAVID WARBRICK-SMITH, Research Assistant

RAYMOND JONES, Research Assistant
Smoking and Health, 1964,* it was made clear (pages 108 and 112) that, while cigarettes shortened life and increased the lung cancer incidence, cigars in moderation-fewer than five a day-did not. This is surprising, since four American cigars are approximately the tobacco equivalent by weight of some 20 to 28 cigarettes. But if the smoker of 20 cigarettes per day has a $70 \%$ higher mortality rate, and a higher death rate from lung cancer than the non-smoker, why should the smoker of the same weight of tobacco in the form of cigars escape so easily?

\section{Present Investigation}

We set out to compare the effect on rats of the smoke of cigarette tobacco with the effect of the smoke of cigar tobacco under identical conditions. $\dagger$ To obtain identical conditions it was necessary to smoke the cigar tobacco in the same form as cigarette tobacco-namely, as cigarettes. So, at our request, and through the courtesy of the Tobacco Research Council, we obtained cigarettes made specially for us consisting entirely of cigar tobacco. The tobacco was cut in the same manner as cigarette tobacco and wrapped in cigarette paper, and in this manner the effects of paper and the different physical conditions of the tobacco were excluded from the experiment.

Groups of young rats were exposed to the smoke of these cigar cigarettes in a cabinet of a Martin Wright Smoking Machine and compared with groups exposed similarly to the smoke of a popular brand of English cigarettes. Control groups were maintained under the same conditions except that they were not exposed to tobacco smoke. All groups were fed Plowco 86 Laboratory Animals' Diet.

*U.S. Department of Health, Education, and Welfare, Public Health Service.

†As it is not possible to induce cancer of the lung in rats by exposure to cigarette smoke, that part of the human sequence of events is not reproducible. 


\section{Pilot Experiment}

On 11 November 1964 white male rats born on 8 October 1964 were divided into three groups: group $A, 12$ rats exposed to cigarette smoke; group B, 12 rats exposed to cigar smoke; and group C, 12 controls rats, non-smokers. Each group had a similar average weight and weight distribution, the mean weight of the animals being $136 \mathrm{~g}$ on Day 1 . Smoking began on Day 13 with 10 cigarettes and increased in steps of five on Days 20,28 , and 62. The animals were smoked daily except on Saturdays and Sundays. Owing to the poor condition of group A, all smoking was suspended on Day 63.

\section{RESULTS}

Each group was free from deaths until Day 62, when three animals in group A died in the smoking cabinet. Without further exposure to smoke, on Day 64 another of the cigarette group died, and two more on Day 67. Yet another death occurred on Day 70, making seven deaths out of 12 animals in
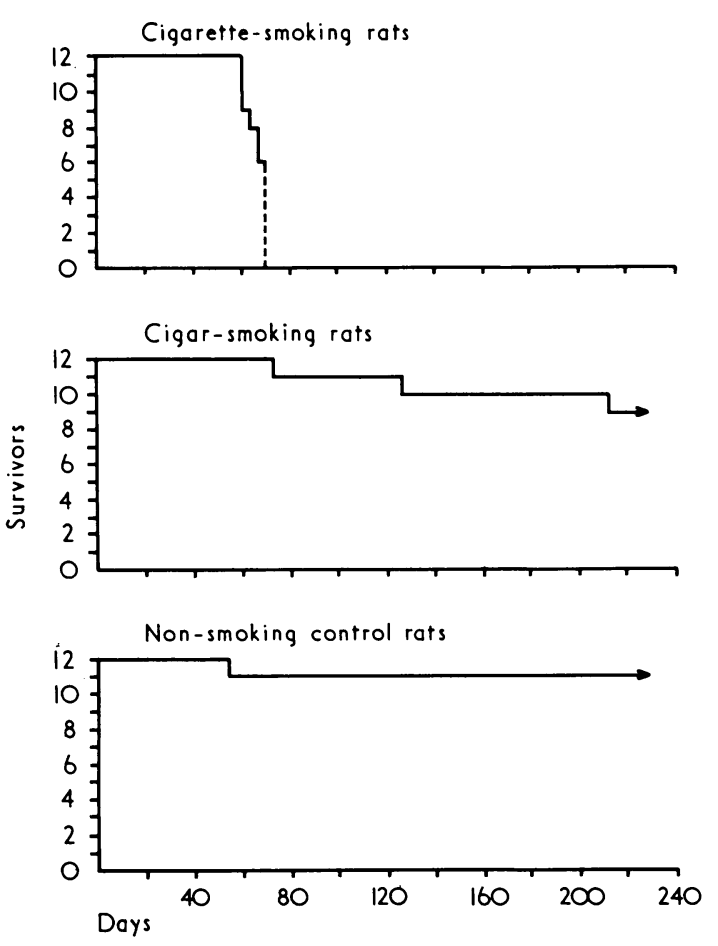

FIG. 1-Results in pilot experiment.

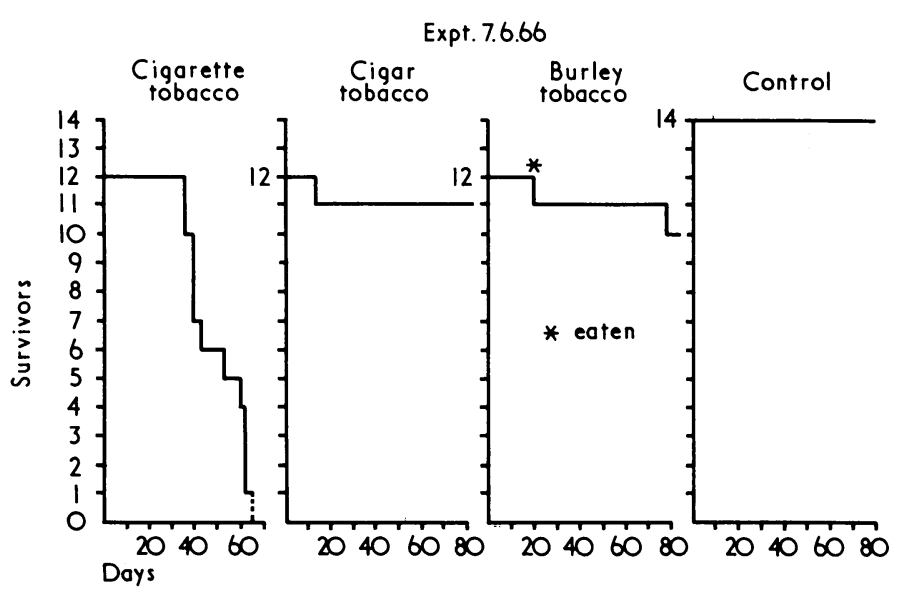

FIG. 2-Results in experiment commenced on 7 June 1966. the cigarette group, the last four deaths occurring after the cessation of smoking. Up to this point no deaths had occurred in either the cigar or control groups. Both groups appeared to be healthy.

The five survivors in group A were killed on Day 70. Compared with group $C$, both groups $A$ and $B$ suffered considerable loss of weight, group A more than group B. This loss of weight is partly a nicotine effect, as has been previously shown (Elson and Passey, 1963).

Smoking of the cigar group was resumed on Day 71 at 20 cigarettes a day, and was then increased to 25 daily on Day 87, to 35 on Day 125, and, finally, to 40 on Day 139. Thereafter the exposure rate was substantially maintained at 40 cigarettes a day until Day 251, when it was decided to close the experiment. During this additional period of 180 days there were six deaths as follows: Day 71, 1 (cause not established); Day 123, 1 (corpse eaten overnight); Day 213, 1 (perirenal abscess, lung healthy); Day 245, 2 and Day 246, 1 (no obvious reason for death). At this point there were still six healthy survivors (Fig. 1). At necropsy no obvious lung lesions were seen. Of the last three deaths, two had occurred in the smoking cabinet and the other during the following night. As not one of these three showed any detectable lesion in either the thorax or the abdomen it was concluded that the cause of death was heatstroke from too high a temperature in the smoking cabinet during the heatwave (July). The six survivors in group B were killed, and at necropsy only one animal presented any lung lesion resembling those in the cigarette group.

Of group C, one animal was killed on Day 52 for unexplained loss of weight. No obvious cause for this was found. The 11 survivors were killed on Day 267. At necropsy they were uniformly healthy except for one animal which showed frank rat bronchiectasis. $f$

This pilot experiment indicated that the smoke of cigar tobacco is relatively harmless compared with that of cigarette tobacco in that only five animals in the cigarette group survived to the 70th day, whereas after much heavier and longer exposure to cigar smoke six animals in the cigar group were alive on the 251st day, presenting little or no cellular damage to their respiratory systems, with even the cilia in the trachea and bronchi remaining intact.

\section{Further Experiments}

As the pilot experiment gave such a striking result further experiments were undertaken. The results were substantially the same as in the pilot experiment in that the animals exposed to the smoke of flue-cured tobacco consistently suffered much more than those exposed to the smoke of cigar and other air-cured tobaccos.

In the experiment of which the results are shown in Fig. 2, another type of cigar tobacco cigarettes (Calypsoß) took the place of the specially-made cigar cigarettes of the pilot experiment, and another air-cured but different type of tobacco (Burley $\|$ ), which is also of very low sugar content and gives rise to an alkaline smoke, was tested in the same manner in the form of cigarettes. The animals in both the Calypso group and the Burley group suffered no more than the cigar group animals of the pilot experiment, confirming that air-cured tobaccos are definitely less damaging to the respiratory system of rats than the flue-cured tobaccos of the English cigarette.

\#at bronchiectasis should not be confused with the condition of bronchiectasis as it occurs in man. It is an entirely different condition.

\$Calypso are trade cigarettes purchasable at many tobacconists and are calypso are trade cigarester The sugar content and the pH of the smoke were comparable to the cigar tobacco cigarette. IAs in the case of the cigar cigarettes, the Burley cigarettes were specially
made for us at our request, and supplied by the Tobacco Research Council. 


\section{Postmortem Findings}

All animals, including the controls, were examined postmortem and except in the case of the pilot experiment the material was examined microscopically. At necropsy the pathological effects as observed were in the main confined to the respiratory and circulatory systems. On opening the chest cavity the lungs of the cigarette animals, when compared with the controls, were often found to be grossly enlarged. This increase in the volume of the lungs is a consistent and striking feature in rats exposed to the smoke of our English cigarettes, but not in those exposed to cigar tobacco smoke (Fig. 3).

Often there was pleural exudate, which was sometimes haemorrhagic, and, less frequently, a peritoneal exudate. At times the trachea was found to be full of mucus which was stained with the products of the smoke. The lungs frequently presented naked-eye evidence of bronchopneumonia, oedema, haemorrhage, and collapse.

Although in some cases pleural and peritoneal watery exudates were encountered, in only one instance was pus found in the pleural cavity and the lungs were adherent to the chest wall. Thus we regarded the exudates as being noninflammatory in nature, and we considered their presence as evidence of circulatory failure. Certainly the heart was often enlarged, while the atria and the veins leading to the heart were engorged and distended with clotted blood. Rightly or wrongly, we regarded these circulatory signs as being, in part at least, secondary to the respiratory distress and disease of the lungs. For this reason we did not study the cardiovascular system, though it might well form material for an entirely different subject of research.

At the end of the experiments all the surviving animals and the controls, were killed. By comparison with the cigarette animals, the cigar animals and the Calypso and Burley animals

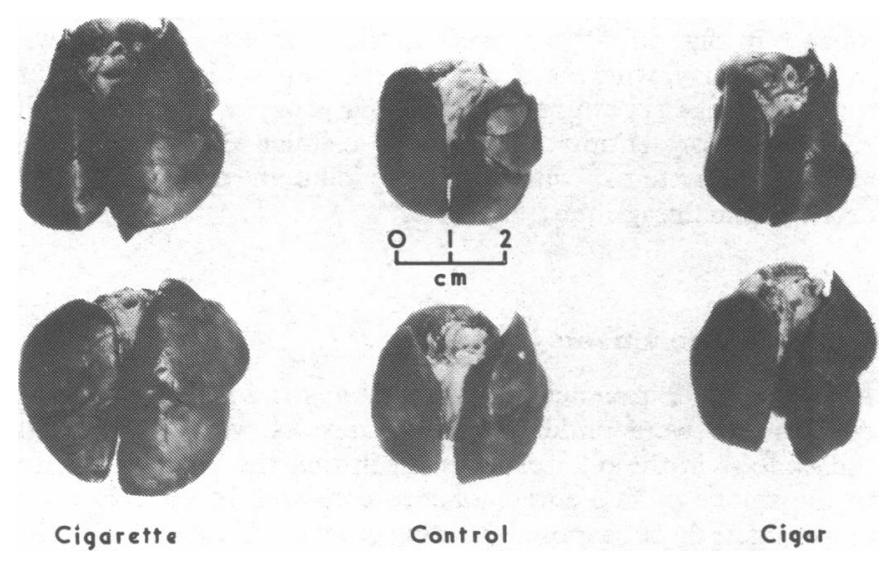

FIG. 3-Postmortem appearances of lungs of rats exposed to cigarette and cigar smoke compared with those of non-smoking controls.

appeared healthy and free from disease. To the naked eye their lungs were very little different from those of the control animals, except that they were often a little enlarged. This can be seen in Fig. 3.

It must be understood that these results seem to depend, to some extent, on the strain of rats. Those used in these experiments appeared to suffer from an endemic rat bronchiectasis. Their respiratory systems seem to be particularly sensitive to the damage which tobacco smoke can inflict. This is supported by a preliminary experiment which was undertaken only once, and which should be repeated. We exposed animals from a pathogen-free strain of white rats to the same dosage of English cigarette smoke as the institute strain. The mortality was lower and was delayed, presumably while infection took the upper hand. Lamb and Reid's (1969) experiments (referred to below) suggest a similar interpretation, as they used a black-and-white Swedish strain descended from a pathogen- free stock. After allowance has been made for the different conditions of the two groups of experiments, their animals seemed to suffer less damage than those in our experiments.

This may well be a reflection of what happens to smokers in England and Wales. The mortality from lung cancer is much higher here than in any other country, while at the same tume the morbidity and the mortality rates for respiratory disease for England and Wales are outstandingly high. In other words, respiratory infection and chronic bronchitis are additional contributing factors to the high lung cancer mortality rate in this country (Passey, 1962).

\section{Miscroscopical Examination}

In the cigarette animals (see Fig. 2) the trachea, the bronchi, and the lungs presented evidence of disease and damage in varying degrees. The trachea and bronchi contained excess of secretions and purulent cellular exudates. The tracheal epithelial lining was frequently hyperplastic and often presented metaplastic changes, sometimes with pronounced squamous changes and complete absence of cilia. In advanced cases the epithelial layers were damaged and disorganized. The mucous glands of the trachea were often enlarged and presented signs of inflammation, very much as described by Lynne Reid (1967) in the case of chronic bronchitis in man. In general, throughout the bronchial tree goblet cells were obviously in excess-in keeping with the excess of mucus. The lungs presented varying degrees of inflammatory disease, and often there was pronounced lymphocytic cuffing of the bronchi, oedema, congestion, collapse, patchy bronchopneumonia, or completely solid bronchopneumonic lobes-in short, a varying picture of tracheitis, bronchitis, and terminal bronchopneumonia, sometimes severe, sometimes slight.

In the cigar groups, on the other hand, the microscope confirmed the naked-eye diagnosis of a relative absence of disease or injury. The lining epithelium of the trachea presented little or none of the inflammatory changes or metaplasia found in the cigarette animals. There was no cellular exudate in the trachea or bronchi, and the cilia were intact. In short, there was little if any disease process observable in the respiratory system. Except for an increase in the goblet cells, the trachea and lungs of the cigar animals did not compare unfavourably with those of the healthy controls. There was, therefore, a striking histological difference between the cigar and the cigarette groups.

Professor Lynne Reid and Dr. Lamb kindly confirmed our histological observations, more especially with regard to the increase in goblet cells and excess of mucus. Furthermore, they carried out experiments of their own with regard to the increase in mitoses which they had observed. This subsequently led to further experiments and to their interesting publication (Lamb and Lynne Reid, 1969). Though their animals were smoked in our smoking chambers and the cigarettes were supplied by ourselves, the conditions of exposure differed from ours in certain respects, so that direct comparison of their results and ours is not strictly possible. Our microscopical material was taken from animals which had died as the result of their exposure to the cigarette smoke, whereas their animals were killed at earlier stages. Again, much of their material came from a strain of rat different from those used in our experiments. Presumably their stock was initially free from endemic infection.

These experiments of Lynne Reid and Lamb confirm our observations that there is a very definite difference in the effects of the flue-cured and air-cured tobaccos, the flue-cured being the more damaging.

\section{Discussion}

A summary of our experiments showed that out of a total of 48 animals exposed to English cigarette tobacco smoke, 
34 had died, showing evidence, in varying degrees, of infective respiratory disease, whereas of 48 exposed to the smoke of cigar tobacco, and 12 exposed to Burley tobacco smoke, only three had died, but none from detectable respiratory disease. Throughout, the conditions of our experiments were the same in all respects except that the tobaccos were different. The English cigarette tobacco was flue-cured, while the cigar and Burley tobaccos were air-cured.

Table of Analysis

\begin{tabular}{|c|c|c|}
\hline & Cigarette & Cigar-Cigarette \\
\hline 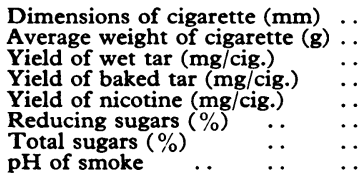 & $\begin{array}{c}70 \times 25 \cdot 6 \\
1 \cdot 10 \\
27 \cdot 6 \\
13 \cdot 4 \\
1 \cdot 40 \\
18 \cdot 1 \\
20 \cdot 3 \\
4\end{array}$ & $\begin{array}{c}70 \times 25 \cdot 6 \\
1.065 \\
23 \cdot 0 \\
9 \cdot 9 \\
1 \cdot 81 \\
0 \cdot 2 \\
0 \cdot 3 \\
9\end{array}$ \\
\hline
\end{tabular}

The accompanying table of analysis of the two types of tobacco which have been used in the experiments reported in this paper shows their main differences: (1) the English cigarette tobacco has a high sugar content, (2) the smoke of cigarette tobacco is acid while that of the cigar tobacco is alkaline, and (3) the English cigarette tobacco yields more tar than air-cured tobacco, but less nicotine.

In this country the main bulk of all tobacco now used in cigarettes is wholly flue-cured, whereas in other countries cigarettes are made of either air-cured tobacco or of air-cured tobacco and other tobaccos blended with flue-cured tobacco in varying quantities. This might account for the different lung cancer mortality rates in different countries.

Flue-curing is a process by which the tobacco is dried by artificial heat in specially constructed barns in the later stages of which temperatures around $170^{\circ} \mathrm{F}\left(76.7^{\circ} \mathrm{C}\right)$ are generated. The whole process may take only some six days. The conditions induced by the high temperatures reached in the process inactivate the enzymes, leaving the natural plant sugars in the tobacco unchanged. These sugars can exceed $25 \%$ or more by weight of the whole flue-cured tobacco. On the other hand, cigar tobacco is air-cured and can be dried in similar barns, but without artificial heat. As the enzymes are not inactivated at the relatively low temperatures attained by this method the natural fermentation of the plant sugars is not interrupted, so that at the end of a drying period of some three months only traces of the sugars remain. It is not a difference in the tobacco plant which gives rise to cigar tobacco or cigarette tobacco, it is the method of drying.

As can be seen from the Table the amount of tar produced by cigarette and cigar tobacco can be significantly different. There are also clear differences in the composition of the tobaccos themselves. Though the precise nature of tobacco tars have not yet been established, they are known to contain recognized carcinogens.

We compared the effect of each type of tar by painting the backs of mice. Because of the difference in the yield of tar from each type of tobacco, due in part no doubt to the sugar in cigarette tobacco, we used the total tar condensates from the same number of cigarettes for each group. Ninety mice (45 males and 45 females) were divided into six groups of 15 . They were painted on five days a week for a total of 174 applications, each group receiving the total tar extracted from 8,000 cigarettes or, as the case might be, cigar-cigarettes. Of the 23 survivors in the cigarette-tar-painted group only one bore a papilloma, which appeared after 168 applications of tar, though after 150 applications 16 our of 24 had shown some ulceration of the painted area. In the cigar-tar group there were nine papillomata in eight mice of the 24 survivors. The first appeared on the 61st application. Microscopically, not one of the skin tumours was found to be malignant. Only 5 out of 24 showed ulceration. There were 24 survivors in the controls and no ulceration or tumours of the skin.

This experiment clearly showed the different nature of the two tars. The tumour-producing effect of cigar tar on the mouse skin paralleled its greater content of chemically recognized carcinogens. The tar of cigarette smoke, though possibly more irritating to the skin, induced only one tumour.

All we can say is that our experiments inciicate that the harm caused by cigarette smoke derives from some unknown constituent in cigarette tobacco smoke, or from the extra tar, or from its acidity. The danger of the cigarette cannot be explained away as being derived from the cigarette paper, because in these experiments cigarette paper was present in both the cigar and the Burley tobacco cigarettes.

The nicotine content in the case of the cigar is, if anything, higher than in the cigarette, yet the cigar smoker suffers less than the smoker of cigarettes. Again, it is not a question of the physical presentation of the tobacco, because in these experiments the cigar and Burley tobaccos are smoked in the same form as in the ordinary cigarette. The carbon monoxide content and the particle size of the three smokes from cigarette, cigar, and Burley tobaccos are very close in each case (Passey and Blackmore, 1966).

\section{Conclusion}

We are forced to conclude that the biological differences, both in man and in our experiments, between the smoke of cigars and that of English cigarettes arise in the nature of the tobaccos, and that this, in turn, is the result of the methods of curing of the tobaccos. The smokes of flue-cured tobaccos are more dangerous to man and to animals than those of air-cured tobaccos.

The analysis of the types of tobacco was carried out through the auspices of Dr. G. Felton, of the Research and Development Establishment of the British-American Tobacco Company Ltd., Southampton.

\section{References}

Elson, L. A., and Passey, R. D. (1963). Acta; Unio internationalis contra cancrum, 19, 715 .

Lamb, D., and Reid, Lynne (1969). British Medical fournal, 1, 33.

Passey, R. D. (1962). Lancet, 2, 107

Passey, R. D., and Blackmore, M. (1966). British Empire Cancer Campaign, 44th Annual Report, p. 6.

Reid, Lynne (1967). Pathology of Emphysema. London, Lloyd-Luke. 